\title{
Using X-ray spectroscopic results to constrain surface complexation models: ferrihydrite
}

\section{JON PETTER GUSTAFSSON ${ }^{1}$, CARIN SJÖSTEDT ${ }^{1}$ AND CHARLOTTA TIBERG ${ }^{2}$}

${ }^{1}$ Swedish University of Agricultural Sciences

${ }^{2}$ Swedish Geotechnical Institute

Presenting Author: jon-petter.gustafsson@slu.se

More than 30 years have passed since Dzombak and Morel [1] published their highly influential work on the use of the Generalized Two-Layer model (GTLM) to describe ion adsorption to ferrihydrite (Fh). Since then, a large number of papers have characterized the coordination environment of adsorbed ions with extended X-ray absorption fine structure (EXAFS) spectroscopy. This, together with recent developments in the knowledge on the surface structure of Fh, and with the advent of new quantitative data on competitive and ternary interactions, has allowed us to develop new surface complexation modelling approaches that more accurately describe ion adsorption. We review existing EXAFS evidence for bivalent metals and oxyanions to show that bidentate coordination prevails among the inner-sphere surface complexes, although additional contributions of monodentate complexes are probable, for example for $\mathrm{AsO}_{3}$. Outer-sphere complexes are also of importance for weakly bound ions such as $\mathrm{SO}_{4}$ and $\mathrm{SeO}_{4}$. Further, ternary complexes are formed that involve bivalent metals and $\mathrm{PO}_{4}$ or $\mathrm{AsO}_{4}$.

These constraints have been integrated into the Simplified Ferrihydrite CD-MUSIC model (SFCD), which combines a stateof-the-art description of the Fh acid-base characteristics [2] with a simplified site distribution that allows high-affinity binding of bivalent metals to $1 \%$ of the sites [3]. We show that the EXAFSconstrained SFCD model not only describes single-sorbate data well, but is also able to describe competitive and electrostatic interactions with common ions such as $\mathrm{Ca}^{2+}, \mathrm{CO}_{3}{ }^{2-}$ and $\mathrm{SO}_{4}{ }^{2-}$ for systems where the GTLM fails. However, there are also examples for which the existing knowledge is insufficient for successful modelling, e.g. for $\mathrm{WO}_{4}{ }^{2-}$. Also, interactions with natural organic matter are still not well understood, and require additional studies.

[1] Dzombak, D.A. \& Morel, F.M.M. (1990), Surface complexation modeling. Hydrous ferric oxide. Wiley; [2] Hiemstra, T. \& Zhao, W. (2016), Environ. Sci. Nano 3, 12651279; [3] Tiberg, C. et al. (2013), Geochim. Cosmochim. Acta $120,140-157$. 